\title{
Determination of Kinetic Constants for Nitrifying Bacteria in Mixed Culture, with the Aid of an Electronic Computer
}

\author{
By G. KNOWLES, A. L. DOWNING AND M. J. BARRETT \\ Water Pollution Research Laboratory, Stevenage, Hertfordshire
}

(Received 1 September 1964)

\begin{abstract}
SUMMARY
An electronic computer was used to integrate differential equations for bacterial growth, and thus to determine simultaneously growth-rate constants, saturation ('Michaelis') constants, and initial numbers of bacteria. In one case numerical methods were necessary to effect the integration and the work would have been prohibitively great if a computer had not been used. By this means curves have been fitted to experimental data on the course of nitrification in water from the Thames Estuary.

Kinetic constants for Nitrosomonas and Nitrobacter at various temperatures were obtained, and the rate of death of these bacteria in the absence of their substrates was estimated.
\end{abstract}

\section{INTRODUCTION}

The activities of ammonia-oxidizing and nitrite-oxidizing bacteria are important in determining both the quality of effluents from biological purification processes for the treatment of domestic and industrial wastes, and the condition of streams, rivers, and estuaries into which such effluents are discharged. To describe quantitatively the influence of these nitrifying organisms in such systems it is necessary to know their growth-constants under the relevant environmental conditions, and the saturation (Michaelis) constants of the substrates which support their growth. It is also desirable to be able to estimate the concentrations of these organisms present in a given sample. A technique for obtaining such information has been developed. This consists essentially in observing the course of nitrification during aeration of appropriate samples when incubated under constant conditions, and then the determination, by trial-and-error, of the values of the kinetic constants and initial concentration of organisms which best fit the observed data. The labour involved would be prohibitive if a desk calculator were used; possibly mainly for this reason the present approach has not received much attention hitherto, but by using an electronic computer most of this labour is eliminated. The method is illustrated below by reference to an examination of the kinetics of nitrification in samples of water from the Thames Estuary.

In the present work it has been convenient to assume that the oxidation of ammonia and nitrite are brought about, respectively, only by Nitrosomonas species and by Nitrobacter species. Nevertheless the existence of at least one other type of nitrifying micro-organism, the ammonia-oxidizing marine organism Nitrocystis, is reasonably well established, and since it is possible that this or other types were active in the samples we examined, the observed growth constants may in fact 
represent an average for a mixed population. Since, however, the main object of this work was to develop a general technique for analysis of data from batch cultures, and since for the study of nitrification in rivers, estuaries and treatment plants information on the combined nitrifying ability of the natural population was in itself of sufficient interest to justify the work, the above simplification was considered adequate. A more complete investigation, however, would necessarily involve identifying the types and strains of organisms present.

\section{Kinetics of growth of nitrifying bacteria}

The kinetics of growth of both organisms (Nitrosomonas, Nitrobacter) appear to conform fairly closely to the following equation of the Michaelis type, as do those of various heterotrophic bacteria (Monod, 1942; Hinshelwood, 1946; Novick \& Szilard, 1950; Herbert, Elsworth \& Telling, 1956):

$$
d C_{\mathrm{m}} / d t=k_{\mathrm{m}} C_{\mathrm{m}} x /(x+X) .
$$

In this context $C_{\mathrm{m}}$ is the concentration of Nitrosomonas in mg./l., as dry matter, $k_{\mathrm{m}}$ its growth-rate constant, $x$ the concentration and $X$ the saturation (or Michaelis) constant of the substrate ammonia, both in $\mathrm{mg} . / \mathrm{l}$. as nitrogen. References to mass and concentration of ammonia, nitrite and nitrate relate throughout to mg. nitrogen and $\mathrm{mg}$. nitrogen per litre respectively. Mass and concentration of bacteria are expressed as dry wt. bacteria (dried at $105^{\circ}$ ). The corresponding equation for the growth of Nitrobacter is

$$
d C_{\mathrm{b}} / d t=k_{\mathrm{b}} C_{\mathrm{b}} y /(y+Y),
$$

in which $y$ is the existing concentration and $Y$ the saturation constant of nitrite, $C_{\mathrm{b}}$ is the concentration and $k_{\mathrm{b}}$ the growth constant of Nitrobacter.

It would perhaps be surprising if this relation exactly represented bacterial growth and it should be mentioned that modifications have been proposed. For example, Boon \& Laudelout (1962) included an extra term in the equation for Nitrobacter to allow for a slight inhibitory effect of the substrate nitrite. However, at the concentrations of nitrite found in the present experiments this term has a negligible effect.

Oxidation of ammonia. If the oxidation of unit mass of ammonia-N produces a dry mass $\boldsymbol{E}_{\mathrm{m}}$ of Nitrosomonas organisms then

$$
C_{\mathrm{m}}-C_{\mathrm{m} 0}=\boldsymbol{E}_{\mathrm{m}}\left(x_{0}-x\right),
$$

in which $x$ is the concentration of ammonia-N, $C_{\mathrm{m}}$ the concentration of Nitrosomonas, and $C_{\mathrm{m} 0}$ and $x_{0}$ are the initial values of $C_{\mathrm{m}}$ and $x$. Combining equations (3) and (1) gives a differential equation that can be integrated to a form already published (Downing, Painter \& Knowles, 1964), which gives the relation between concentration of ammonia-N and time:

where

$$
k_{\mathrm{m}} t=(\mathbf{1} / A)\left[\boldsymbol{E}_{\mathrm{m}} X \log _{\mathrm{e}}\left(x_{0} / x\right)+\left(A+E_{\mathrm{m}} X\right) \log _{\mathrm{e}}\left\{\left(A-\boldsymbol{E}_{\mathrm{m}} X\right) / C_{\mathrm{m} 0}\right\}\right],
$$

Solutions to this equation, calculated by using an electronic digital computer, were matched against the observations, described later, in order to determine the best values for $k_{\mathrm{m}}, C_{\mathrm{m} 0}$ and $X$, the programme for the machine being so devised that trial values for these variables could be chosen over as wide a range as desired. The yield 
constant, $E_{\mathrm{m}}$, was taken as $\mathbf{0 \cdot 0 5}$, this choice being perhaps a little low on evidence quoted by Downing et al. (1964) and also on unpublished work at this Laboratory (Painter \& Loveless, in preparation). An incorrect value for $\boldsymbol{E}_{\mathrm{m}}$ would, however, affect only the estimate of $C_{\mathrm{m} 0}$, but not those of $k_{\mathrm{m}}$ and $X$. The estimated value of $C_{\mathrm{m} 0}$ is in fact proportional to the assumed value of $E_{\mathrm{m}}$. This can be seen from equation (4), which remains unaltered if $\mathrm{C}_{\mathrm{mo}}$ and $E_{\mathrm{m}}$ are multiplied by the same factor. Figure $1(a)$ shows an example of the agreement between the observed and calculated curves when the values of $k_{\mathrm{m}}, C_{\mathrm{m} 0}$ and $X$ have been properly chosen.
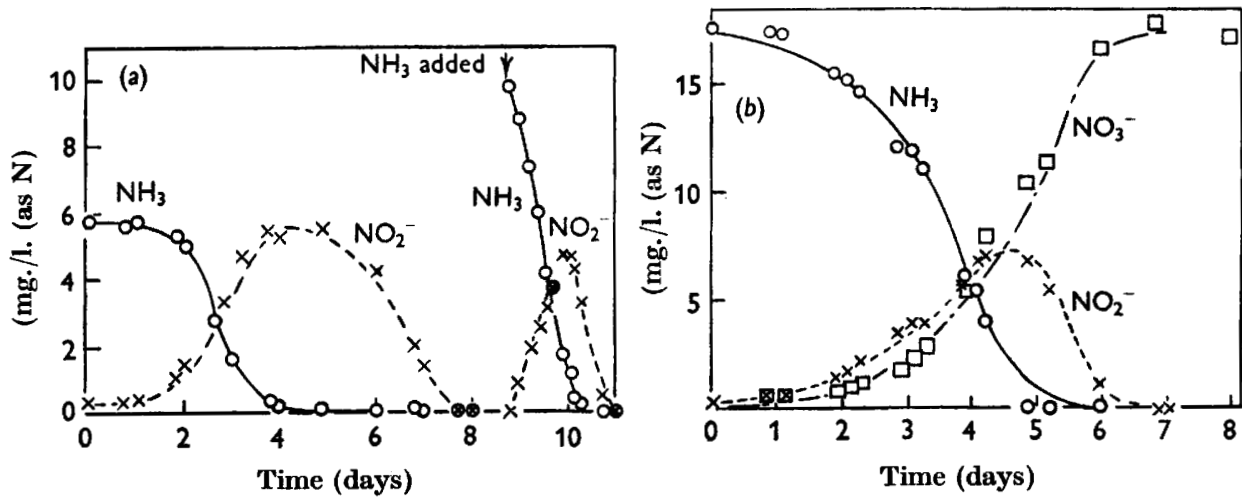

Fig. 1. Examples of computed curves which best fit observations on the course of nitrification during incubation of water from the Thames Estuary. (a) An experiment in Series 2, Table 1. Temperature $29 \cdot 3^{\circ}$ until day $8,30 \cdot 8^{\circ}$ thereafter; more ammonia was added on day 9. (b) An experiment in Series 4, Table 1. O, ammonia observed; $x$, nitrite observed; $\square$, nitrate observed; - , ammonia computed ; - - -, nitrite computed; $\cdots$, nitrate computed.

One of the problems was to decide whether or not any set of values of $k_{\mathrm{m}}, C_{\mathrm{m} 0}$ and $X$, giving an apparently satisfactory fit to the observed data, represented a unique solution or whether some other combination of these variables would have given an equally good fit. This problem was, however, made easier by the fact that the value of $X$ appears to be quite low and hardly affected the shape of the ammoniatime curve at concentrations of ammonia- $\mathrm{N}$ above about $1 \mathrm{mg} . / \mathrm{l}$.

The idea that any combination of values which gave a good fit would be unique was supported by the fact that a second such combination which fitted equally well was never obtained, and also by the general consistency of the results, both among themselves and also as compared with other published data.

Apart from such general support, it can be shown from equation (1) (which after substituting $-E_{\mathrm{m}} d x / d t$ for $d C_{\mathrm{m}} / d t$ gives the slope, $d x / d t$, of the ammonia-time curves) that only the correct value of $k_{\mathrm{m}}$ will give a curve passing through two experimental points, provided that the first of these points was so chosen that $(a)$ the concentration of ammonia oxidized since the beginning of the experiment was sufficient to make $C_{\mathrm{m}}$ large compared with $C_{\mathrm{m} 0}$ and $(b) X$ had been correctly chosen or was small compared with $x$. (For any particular value of $x$, condition $(a)$ ensured that all curves through one point applied to substantially the same concentration of Nitrosomonas and condition $(b)$ that all such curves had substantially the same value for $x /(x+X)$.) Suppose, for instance, the correct curve was drawn through two 
such points, and that $k_{\mathrm{m}}$ was of value $k$, then any other curve through the points must, somewhere between them, have a greater slope than the first curve, and somewhere else have a smaller slope. Where the curve has a greater slope than the correct curve at the same ammonia concentration then equation (1) shows it has a $k_{\mathrm{m}}$ value greater than $k$, for by equation(3) and condition (a) above $C_{\mathrm{m}}$ is the same for both

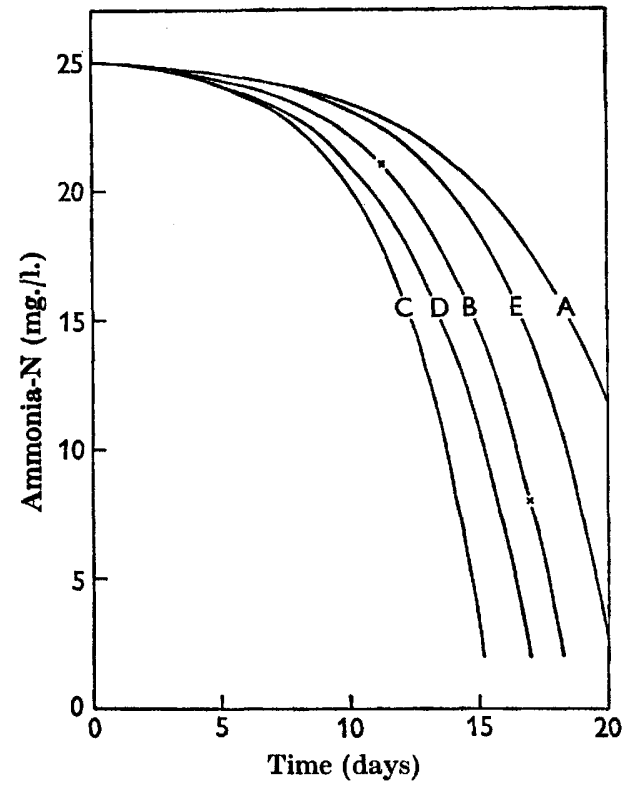

Fig. 2

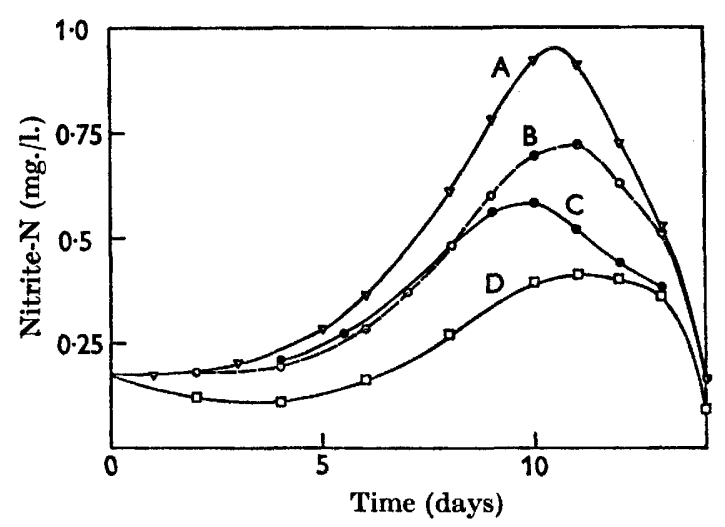

Fig. 3

Fig. 2. Effects of values of growth constant and initial concentration of Nitrosomonas on shape and position of computed ammonia-time curves.

\begin{tabular}{|c|c|c|c|}
\hline $\left.\begin{array}{l}\text { A } \\
\text { B } \\
\text { C } \\
\text { D } \\
\text { E }\end{array}\right\}$ Growth constant & $\left\{\begin{array}{l}0 \cdot 20 \\
0 \cdot 25 \\
0 \cdot 30 \\
0 \cdot 25 \\
0 \cdot 25\end{array}\right)$ & day $^{-1}$; initial concentration of Nitrosomonas & $\left\{\begin{array}{l}0.016 \mathrm{mg} . / \mathrm{l} . \\
0.016 \mathrm{mg} . / 1 . \\
0.016 \mathrm{mg} . / \mathrm{l} . \\
0.022 \mathrm{mg} . / 1 . \\
0.010 \mathrm{mg} . / \mathrm{l} .\end{array}\right.$ \\
\hline
\end{tabular}

Saturation constant, $0.36 \mathrm{mg} . / 1$. in each case; $\times$, points referred to in text under the heading 'Oxidation of ammonia'.

Fig. 3. Effects of initial concentration and saturation constant of Nitrobacter on shape and position of computed nitrite-time curves.

$$
\left.\begin{array}{l}
\text { A } \\
B \\
C \\
D
\end{array}\right\} \text { Initial concentration }\left\{\begin{array}{l}
0.001 \\
0.002 \\
0.001 \\
0.004
\end{array}\right\} \text { mg./1.; saturation constant }\left\{\begin{array}{l}
2 \mathrm{mg} . / 1 . \mathrm{N} \\
2 \mathrm{mg} . / \mathrm{l} . \mathrm{N} \\
1.5 \mathrm{mg} . / \mathrm{l} . \mathrm{N} \\
1.5 \mathrm{mg} . / 1 . \mathrm{N}
\end{array}\right.
$$

Growth constant 2 days $^{-1}$ in each case.

curves, and by condition $(b)$ so is $x /(x+X)$. Similarly, where the curve has a smaller slope it has a $k_{\mathrm{m}}$ value smaller than $k$. Therefore it does not have a constant value for $k_{\mathrm{m}}$ and so cannot be a solution. Such points, in Fig. 2, are $21 \mathrm{mg}$./l. at 11.3 days and $8 \mathrm{mg}$./l. at 17 days; only curve $B$ goes through both points. Thus, when a fit is obtained to a number of points along an appropriate part of the ammonia-time curve it is very probable that the correct $k_{\mathrm{m}}$ value has been used. Having established 
a value of $k_{\mathrm{m}}$ by the middle part of an ammonia-time curve then an argument similar to the above shows that the values of $X$ obtained from the fit to the later part of the curve are correct, subject to the accuracy of the determinations of low concentrations of ammonia.

For estimating $C_{\mathrm{m} 0}$, the initial concentration of Nitrosomonas, it is assumed that no lag-phase intervened between taking the sample and continuance of growth with a steady growth-rate constant. This assumption is made on the ground that, except when the incubation temperature was different from that in the estuary, the bacteria probably did not necessarily undergo any great change in their chemical environment or physical conditions on being transferred from the estuary to the sample bottle. When the incubation temperature was low the changes in concentration of ammonia in the early stages were too small to provide evidence of a lag-phase. There is certainly no indication of such a lag where the incubation temperature was of the order of $30^{\circ}$, since the concentration of ammonia decreased rapidly from zero time, giving an experimental curve that can be well fitted throughout by equation (4), using fixed values of $k_{\mathrm{m}}, C_{\mathrm{m} 0}$ and $X$. When in any experiment a lagphase did occur, the effect would be that the estimate of $C_{\mathrm{m} 0}$ would be too low, but that the estimate of $k_{\mathrm{m}}$, essentially based on fitting those parts of the experimental curve which show definite curvature, would be correct. In passing it may be noted that while only one set of values of $k_{\mathrm{m}}, C_{\mathrm{m} 0}$ and $X$ would genuinely fit perfect data, the precision with which these values can be selected is, of course, in practice dependent on the accuracy of the observations.

Oxidation of nitrite. In extending the calculations to the changes in concentration of nitrite with time the concentration of Nitrobacter is given by an equation like equation (3), viz.:

$$
C_{\mathrm{b}}-C_{\mathrm{b} 0}=E_{\mathrm{b}}\left\{y_{0}+f_{\mathrm{m}}\left(x_{0}-x\right)-y\right\}
$$

where $y$ is the concentration of nitrite- $\mathrm{N}, C_{\mathrm{b}}$ the concentration of Nitrobacter, $C_{\mathrm{b} 0}$ and $y_{0}$ are the initial values of $C_{\mathrm{b}}$ and $y, f_{\mathrm{m}}$ is the ratio of the mass of nitrite- $\mathrm{N}$ formed to that of ammonia-N oxidized, and where the oxidation of unit mass of nitrite-N produces a dry mass $E_{\mathrm{b}}$ of Nitrobacter.

The approximate constancy of the total amount of inorganic nitrogen present throughout the period of incubation (as shown, for example, in Fig. $1 b$ ) indicates that the value of $f_{\mathrm{m}}$ is close to unity; it has been taken as 0.99 in the present calculations.

Substituting the value of $C_{\mathrm{m}}$ given by equation (3) into equation (1) we then have a differential equation for the variation of ammonia- $\mathrm{N}$ with time, which may be summarized as

$$
d x / d t=\phi_{1}\left(C_{\mathrm{m} 0}, x_{0}, x, X, k_{\mathrm{m}}, E_{\mathrm{m}}\right)
$$

the integrated form of which is equation (4). Similarly, substituting the value of $C_{\mathrm{b}}$ given by equation (5) in equation (2) gives a differential equation for the variation of nitrite- $\mathbf{N}$ with time, summarized as

$$
d y / d t=\phi_{2}\left(C_{\mathrm{b} 0}, x, y_{0}, y, Y, k_{\mathrm{b}}, E_{\mathrm{b}}\right) \text {. }
$$

$\phi_{1}\left(\right.$ ) and $\phi_{2}$ ( ) are general expressions for functions. The occurrence of $x$ in the expression for $d y / d t$, together with the involved relation between $x$ and $t$ given in equation (4), makes it impossible to integrate equation (7) to an explicit relation between nitrite concentration, $y$, and time, $t$. Accordingly equation (7) was treated 
by 'numerical integration' to obtain a predicted curve for concentration of nitrite against time for any chosen set of values for $C_{\mathrm{b} 0}, k_{\mathrm{b}}$, and $\boldsymbol{Y}$. From the evidence quoted by Downing et al. (1964) $E_{\mathrm{b}}$, the mass of Nitrobacter formed per unit mass of nitrite-N oxidized, was taken as $0 \cdot 02$; choice of a wrong value for $\boldsymbol{E}_{\mathrm{b}}$ would affect the estimation of the initial concentration of bacteria (the result being proportional to the value chosen for $E_{\mathrm{b}}$ ) but would not affect the estimates of growth-rate and saturation constants.

By combining differential equations (6) and (7) with a 'subroutine' based on the Runge-Kutta-Merson procedure (Fox, 1962), and supplied by the makers of the digital computer used, a single program was formed, which gave predicted curves for many sets of $C_{\mathrm{b} 0}, k_{\mathrm{b}}$, and $Y$ at the rate of about one every $2 \mathrm{~min}$. (with a desk calculator about $20 \mathrm{hr}$ was required for each curve). The values used for $C_{\mathrm{m} 0}$, $k_{\mathrm{m}}$ and $X$ were those that had been found, as described earlier, to give the best fit to the ammonia-time curve.

The availability of such a numerical integration 'subroutine' is of great assistance in writing a programme for solving simultaneous differential equations. Makers of computers are usually able to supply a version of the Runge-Kutta process programmed in a language suitable for their machines, while for workers using the 'universal' computer language, Algol, a programme published by Lukehart (1963) for the Runge-Kutta-Merson method is suitable.

In this way were determined values of $C_{\mathrm{b} 0}, k_{\mathrm{b}}$ and $Y$ for Nitrobacter that gave the best fit to the experimental points; examples of such best fits are shown in Fig. 1. From the many trials made, it seemed that, as for Nitrosomonas, a good fit could be obtained only with a particular set of values of these three unknowns except in one or two cases in which a completely satisfactory fit could not be obtained with any combination. The predicted curves were much altered by variation in any of the unknowns, the nature of the change depending on the unknown concerned. For example, in Fig. 3 the change from $A$ to $C$ is produced by decrease of the saturation constant from 2 to $1.5 \mathrm{mg}$./1., from $\mathrm{A}$ to $\mathrm{B}$ by increasing the assumed initial concentration of Nitrobacter from 0.001 to $0.002 \mathrm{mg}$./l., and from $\mathrm{C}$ to $\mathrm{D}$ by increasing this from 0.001 to $0.004 \mathrm{mg}$./ . As in the case of Nitrosomonas, when a lag-phase were present the estimates of $\mathrm{C}_{\mathrm{b} 0}$, the initial concentration of Nitrobacter, would be too low.

The prediction of the change in concentration of nitrate with time was made from the best fit kinetic constants and values of $C_{\mathrm{m} 0}$ and $C_{\mathrm{b} 0}$, assuming that unit mass of nitrite- $\mathrm{N}$ forms 0.99 unit mass of nitrate- $\mathrm{N}$ on oxidation. This assumption appears to be justified by the close fit so obtained, as illustrated for example in Fig. $1 b$.

\section{METHODS}

Five series of experiments were made, the objectives being to study the way in which the kinetic constants of nitrifying bacteria were affected by temperature, by aeration in the absence of the energy source (ammonia or nitrite) and by concentration of dissolved oxygen, and to examine the possibility that a relation exists between estimated concentrations of nitrifying bacteria in Thames water and the concentration of suspended matter. The first four series were made in 1960 and the fifth in 1963.

Series 1. Subsamples from 50 (British Imperial) gallons (about 227 l.) of water, 
from the Thames Estuary near London Bridge, were incubated, without dilution, in $10 \mathrm{l}$. aspirators in three constant-temperature rooms at about $7.5^{\circ}, 14^{\circ}$ and $20^{\circ}$. Two experiments were made in each room, one with the water as taken, and the other with the addition of ammonium sulphate to raise the initial concentration of ammonia-N by about $6 \mathrm{mg}$./l. Solids present in each sample were kept in suspension with magnetic stirrers. Each aspirator was completely filled and the mouth of the vessel closed by a rubber stopper, care being taken to exclude air when the stopper was inserted. Samples were generally taken daily from each vessel by removing the stopper and allowing water to flow through a side arm near the bottom. Concentrations of dissolved oxygen, $\mathrm{NH}_{3}-\mathrm{N}, \mathrm{NO}_{2}-\mathrm{N}$ and total oxidized-N $\left(\mathrm{NO}_{2}-\mathrm{N}\right.$ plus $\mathrm{NO}_{3}-\mathrm{N}$ ) were measured in each sample.

Complete filling of the aspirator was not essential for the aspects now under discussion but was done for the purpose of measuring the rate of consumption of dissolved oxygen. When necessary the contents of the aspirator were aerated by shaking in contact with air, an additional small sample being taken for determination of dissolved oxygen. The aspirator was then replenished from another that was open to the air and contained a further portion of the original sample of Thames water. In calculating the results of the experiments, allowance was made for the slightly different composition of the replacement water. This allowance was a very small one because the analyses for ammonia, nitrite and nitrate gave similar figures for aspirator contents and replenishment water (which indicated similar growth of nitrifying bacteria), and especially because the volume of water used per day for replenishment was only about $2 \%$ of the total volume of the sample. From these considerations it was clear that the replenishment would not significantly change either the concentration of the nitrifying bacteria or the general biological conditions.

The same analytical methods were used in all series of experiments.

Ammonia-N was determined by distillation of the sample from a borax buffer solution, nesslerization of the distillate, and measurement of the extinction in a Spekker absorptiometer.

Total oxidized-N was determined by reduction of a $50 \mathrm{ml}$. sample with Devarda's alloy in the presence of $5 \mathrm{ml}$. of $8 \%(\mathrm{w} / \mathrm{v})$ sodium hydroxide solution, followed by distillation and then nesslerization of a suitable sample of the distillate. A weighed amount (1 g.) of Devarda's alloy was used, and a blank determination was made for each series of analyses.

$\mathrm{NO}_{2}-\mathrm{N}$ was measured by using Griess-Ilosvay reagent according to the procedure recommended by the Ministry of Housing and Local Government (1956).

Dissolved oxygen was measured by the azide modification of the Winkler method, as recommended by the Ministry of Housing and Local Government (1956).

Series 2 . Thames water containing nearly $3 \mathrm{mg} . / \mathrm{l}$. ammonia-N (taken from about the same position as the water used in Series 1) was incubated without dilution, at about $28^{\circ}$ in three vessels with the addition of ammonium sulphate equivalent to $0,2 \cdot 5$, and $5 \mathrm{mg}$./l. ammonia-N. On the ninth day (by which time nitrification was complete) a further quantity of ammonium sulphate was added to each vessel to give concentrations of 2,10 , and $20 \mathrm{mg} . / 1$. ammonia- $\mathrm{N}$, respectively, and the incubation continued. The techniques used in Series 1 were again used, except that the oxygen content of the water was replenished as necessary by bubbling oxygen through it for short intervals to give initial concentrations of $12-15 \mathrm{mg} . / \mathrm{l}$. 
Series 3 and 4. It was evident from the results of the tests made in Series 1 and 2 that the quantity of nitrifying bacteria in the Thames water was fairly small, so before starting Series 3 and 4, in which the effect of the concentration of dissolved oxygen on the nitrification process was examined, the sample of Thames water was stored at $19^{\circ}$ (the temperature of the subsequent incubation) for several days to obtain a larger population of nitrifying organisms by the oxidation of the ammonia$\mathrm{N}$ present initially. The water was then fortified with ammonium sulphate equivalent to $18 \mathrm{mg} . / 1$. ammonia-N, and incubated in six vessels. A different oxygen content was maintained in each vessel by aerating with mixtures of air, nitrogen, and carbon dioxide. The rate of flow of each gas was measured by a rotameter, the total rate of flow being about the same in each vessel. The partial pressure of the carbon dioxide in the gas mixture was adjusted to a value that would maintain the concentration of free carbon dioxide that was present in the water at the beginning of the experiment. The required rate was obtained in a subsidiary experiment by adjusting the rate of flow to maintain the initial $\mathrm{pH}$ value of the water. Subsequent experiments, and work reported elsewhere (Department of Scientific and Industrial Research, 1964) indicate that loss of ammonia by volatilization during the experiments was unlikely to be of significant proportions.

Series 5. In these experiments the progress of nitrification was measured in a series of five samples taken from the Thames Estuary at London Bridge on the same day and from the same depth but at different states of tide; the concentration of suspended matter in the samples ranged from about 100 to $1000 \mathrm{mg}$./1., and the object was to examine whether or not the initial concentration of nitrifying bacteria bore any relation to that of suspended solids. It was thought that such a relation might exist if nitrifying bacteria became bound up in the estuary with suspended mud particles, which tend to be flocculent in nature, and that since the concentration of suspended mud varied with the state of the tide so too might that of the nitrifying bacteria; however, no significant relation was found. The procedure was similar to that in the experiments of Series 3 and 4, except that normal air was used for aeration.

\section{RESULTS}

Table 1 gives details of the results of the five series of tests.

\section{Growth constants}

Effect of temperature. It will be seen from Table 1 and also from Figs. 4 and 5 that the growth constants of the organisms present in Sample 1 increased considerably with increasing temperature in the range from 8 to $23^{\circ}$. The equation of the regression line fitted to the data for Nitrosomonas is

$$
\log _{10} k_{\mathrm{m}}=0 \cdot 0413 T-0.944
$$

(with $k_{\mathrm{m}}$ in day $^{-1}$ and $T$ in ${ }^{\circ} \mathrm{C}$.), the implication of which is that the growth-rate constant increased by about $9.5 \%$ of the existing value per degree Centigrade increase in temperature. The corresponding equation for Nitrobacter is

$$
\log _{10} k_{\mathrm{b}}=0.0255 T-0.492
$$

(with $k_{\mathrm{b}}$ in day $^{-1}$ and $T$ in ${ }^{\circ} \mathrm{C}$.), implying that the temperature coefficient for this organism was about $5.9 \% / \mathrm{deg}$. It is also evident that at a given temperature the value 

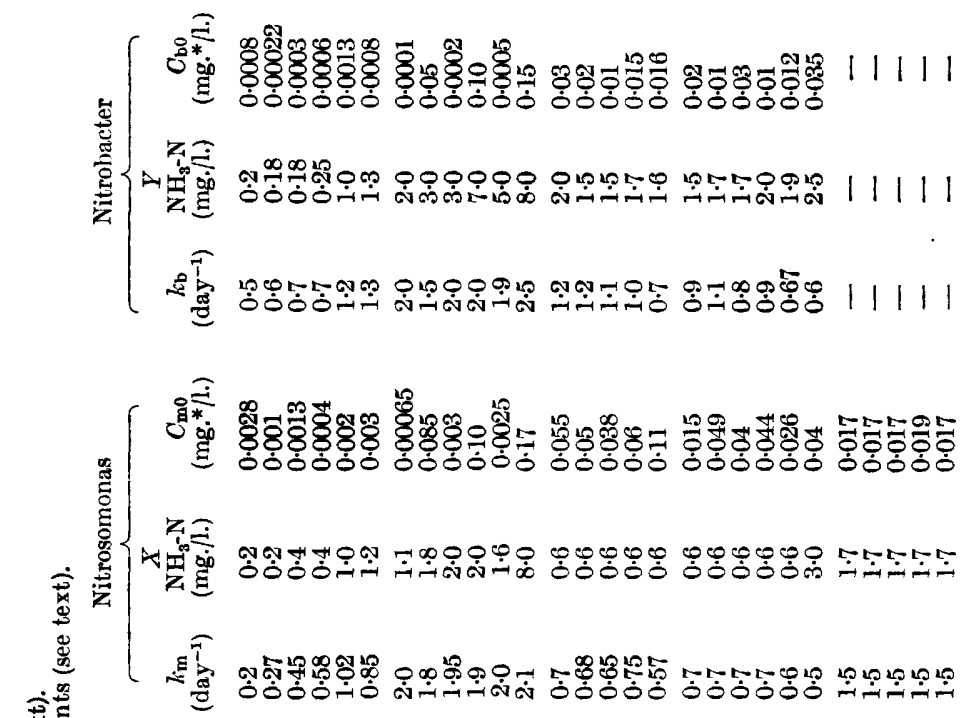

. 茟 है

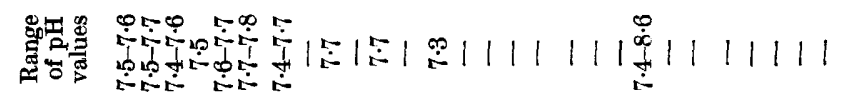

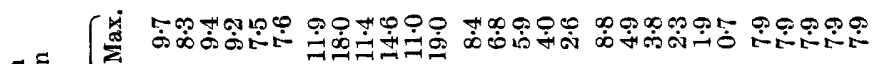

OP

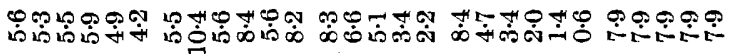

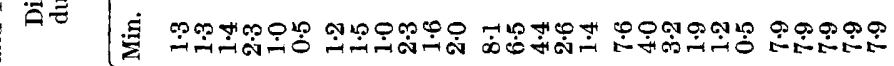

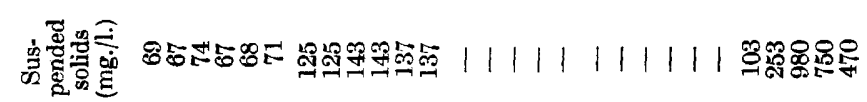

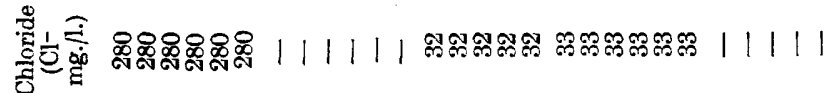

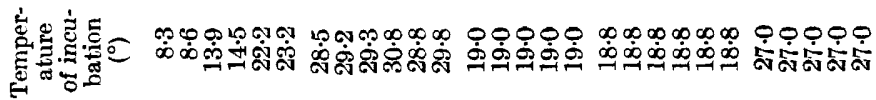

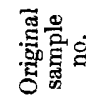

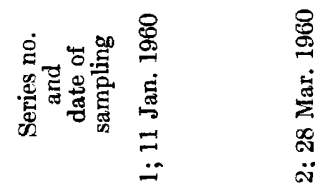


of the growth-rate constant for Nitrobacter was about $50 \%$ greater than that for Nitrosomonas. Data for the remaining Samples 2-5 appear to be in good agreement with the trends of those from Sample 1.

Buswell, Shiota, Lawrence \& van Meter (1954) studied the effect of temperature on the growth of pure cultures of Nitrosomonas and obtained values of $k_{\mathrm{m}}$ increasing from about $0.5 \mathrm{day}^{-1}$ at $15^{\circ}$ to about 2 days $^{-1}$ at $32^{\circ}$; the temperature coefficient

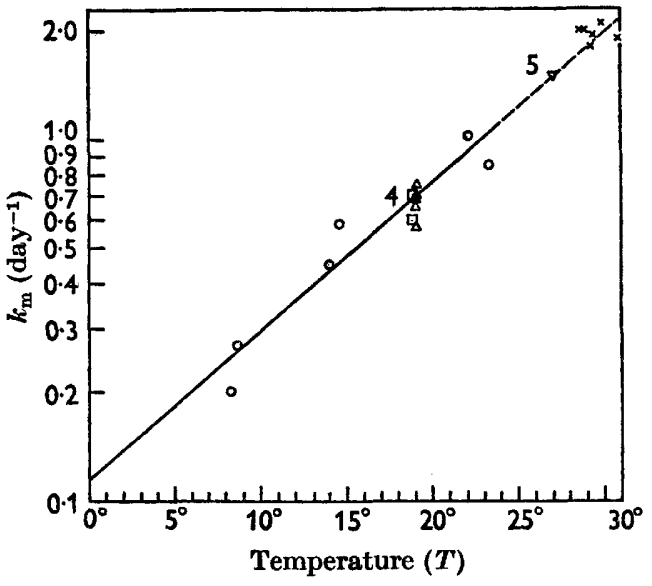

Fig. 4.

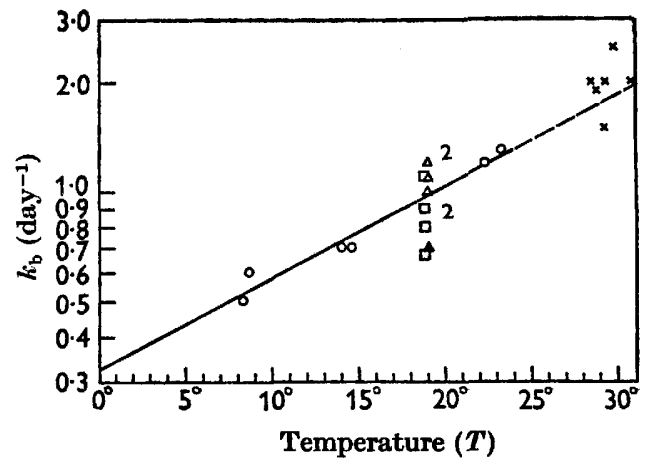

Fig. 5

Fig. 4. Effect of temperature on the growth-rate constant for Nitrosomonas. Regression line is fitted to the points for Sample 1, Table 1. O, Sample 1; $\times$, Sample 2; $\Delta$, Sample 3; $\square$, Sample $4 ; \nabla$, Sample 5. A number alongside a point shows the number of determinations giving a value represented by that single point.

Fig. 5. Effect of temperature on the growth-rate constant for Nitrobacter. Regression line is fitted to the points for Sample 1, Table 1. 0 , Sample 1; $\times$, Sample 2; $\Delta$, Sample 3; $\square$, Sample 4. A number alongside a point shows the number of determinations giving a value represented by that single point.

calculated from these data is $8.2 \% / \mathrm{deg}$. A similar effect of temperature on the growth of Nitrosomonas in activated sludge from a sewage-treatment plant was reported by Downing et al. (1964) and by Downing \& Hopwood (1965). The magnitude of $k_{\mathrm{m}}$ at a given tempeturera is known to depend on the $\mathrm{pH}$ value of the medium and its composition. At temperatures of about $30^{\circ}$, for which $k_{\mathrm{m}}$ in the present work ranged from about $1 \cdot 6$ to $2 \cdot 0$ days $^{-1}$, the following values (all in days ${ }^{-1}$ ) were reported for pure batch cultures grown in medium containing mineral solids : 1.19 (Engel, 1930), 1.03 (Bömeke, 1946), 0.46 (Lees, 1952), and 1.5 (Engel \& Alexander, 1958). Skinner \& Walker (1961) obtained a figure of 3.1 days ${ }^{-1}$ during continuous culture, with a clear medium of composition adjusted to give maximum growth rates. Painter \& Loveless (unpublished work in this Laboratory) obtained maximum values of $k_{\mathrm{m}}$ of about 0.7 to 0.9 day $^{-1}$ at $25^{\circ}$ and $\mathrm{pH} 7 \cdot 6-8.0$ in batch cultures in a clear medium; beyond this range they found that growth rates decreased markedly. For comparison with the growth-rate constants found for Nitrobacter there appears to be only a figure of 1.39 day $^{-1}$ at $32^{\circ}$ obtained by Boon $\&$ Laudelout (1962) with a pure culture; this is only about half the corresponding value in the present work. 
Effect of concentration of dissolved oxygen. Results for Series 3 and 4, Table 1, indicate that $k_{\mathrm{m}}$ varied little with concentration of dissolved oxygen above $2 \mathrm{mg}$. $/ \mathrm{l}$. but decreased with decrease in concentration below $2 \mathrm{mg} . / 1 . ; k_{\mathrm{b}}$ appeared to decrease with decreasing concentration of dissolved oxygen below $4 \mathrm{mg}$./l. The effect on $k_{\mathrm{m}}$ was only qualitatively consistent with the effect of dissolved oxygen on the instantaneous rate of respiration of Nitrosomonas in activated sludge (Downing et al.

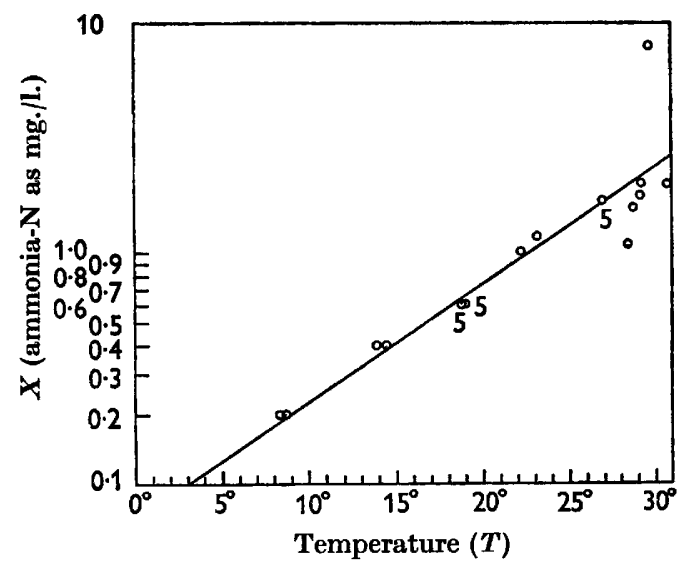

Fig. 6

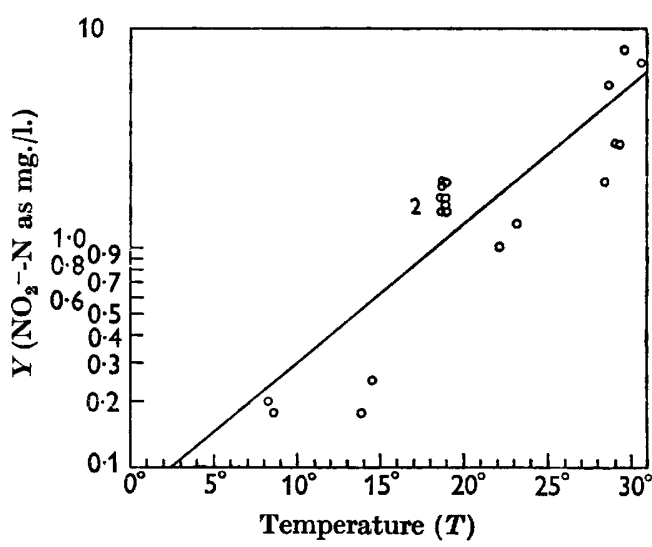

Fig. 7

Fig. 6. Effect of temperature on saturation constant for Nitrosomonas. Regression line is fitted to all points; Samples 1 to 5 , Table 1. A number alongside a point shows the number of determinations giving a value represented by that single point.

Fig. 7. Effect of temperature on saturation constant for Nitrobacter. Regression line is fitted to all points, (Samples 1 to 5, Table 1. A number alongside a point shows the number of determinations giving a value represented by that single point.

1964) and in soil (Greenwood, 1962). The difference in detail may indicate a genuine difference in the long-term effect on growth as compared with the short-term effect on function. With regard to the effect on $k_{\mathrm{b}}$, Boon \& Laudelout (1962) found the saturation constant for oxygen was 0.25 at $18^{\circ}$ and $0.5 \mathrm{mg}$./1. at $32^{\circ}$. These data are not necessarily inconsistent with those in Table 1, although they are perhaps lower than the latter might lead one to expect.

\section{Saturation constants}

All the estimates of the saturation constants of ammonia-N (for Nitrosomonas) and nitrite-N (for Nitrobacter), other than values obtained in experiments in which the concentration of dissolved oxygen was below $1 \mathrm{mg} . / \mathrm{l}$. for a significant period, are plotted against temperature in Figs. 6 and 7. It is seen that at temperatures below about $20^{\circ}$ the values for ammonia and nitrite were of the same order but, whereas the values for both substrates increased with temperature, the rate of increase in the values for nitrite appeared to be higher than in those for ammonia.

As regards the saturation constant of ammonia- $\mathbf{N}$ for Nitrosomonas there is little to afford a comparison with the values shown in Fig. 6, other than a value of $0 \cdot 2$ mg./l. at $21^{\circ}$ obtained at this Laboratory by Dr H. A. Painter (but this was for activated sludge from a sewage-treatment plant) and an approximate value of 
$10 \mathrm{mg} . / \mathrm{l}$. at $30^{\circ}$ calculated by Downing et al. (1964) from data by Hofman \& Lees (1953). Accordingly, Fig. 6 appears to be the first evidence for a large temperature coefficient of the saturation constant for ammonia (Nitrosomonas). The equation of the regression line in Fig. 6 is

$$
\log _{10} X=0 \cdot 051 T-1 \cdot 158
$$

(with $X$ in mg./l. $\mathbf{N}$ and $T$ in ${ }^{\circ} \mathrm{C}$.); this corresponds to an increase in saturation constant of about $11.8 \%$ of the existing value per degree Centigrade increase in temperature.

The saturation constants found for nitrite- $\mathrm{N}$ are in good agreement with the figure for pure culture of Nitrobacter $\left(6 \mathrm{mg}\right.$. $/ 1$. at $\left.30^{\circ}\right)$ calculated by Downing et al. (1964) from the data of Lees \& Simpson (1954), and of $8.4 \mathrm{mg} . / \mathrm{l}$. at $32^{\circ}$ found by Laudelout \& van Tichelen (1960), though the latter is different from the value of $22 \mathrm{mg}$./1. at $32^{\circ}$ given by Boon \& Laudelout (1962). Laudelout \& van Tichelen found an appreciable temperature coefficient (though not so large as that determined in the present experiments), their values being $1 \cdot 4 \mathrm{mg} . / 1$ at $14^{\circ}, 2 \cdot 1 \mathrm{mg} . / 1$. at $18^{\circ}, 8 \cdot 4 \mathrm{mg} . / \mathrm{l}$. at $32^{\circ}$. The equation of the regression line fitted to our values in Fig. 7 is

$$
\log _{10} Y=0 \cdot 063 T-1 \cdot 149
$$

(with $\boldsymbol{Y}$ in mg./l. $\mathbf{N}$ and $T$ in ${ }^{\circ} \mathrm{C}$.); this corresponds to a temperature coefficient of about $14.5 \%$ per degree.

The actual values of $X$ and $Y$ (particularly $X$ ) for Series 4, last subsample, in which the concentration of dissolved oxygen was maintained at a very low value, are higher than expected from the results on other subsamples from the same and other series; this may represent not a true change in $X$ and $Y$ but the existence, in the growth-rate equation, of a term containing dissolved-oxygen concentration but having a significant effect on growth rate only at low concentrations of dissolved oxygen.

\section{Initial concentrations, $C_{\mathrm{m} 0}, C_{\mathrm{bo}}$}

It will be seen from Table 1 that for each separate group of subsamples derived from Samples 1 to 4 there was considerable variation in the estimated initial concentrations of nitrifying bacteria, but whereas the average values for each series varied by about a factor of 30 , the range of variation of the estimates within each group was between limits only of about 2 and 0.5 times the mean value (neglecting one very low figure in the group of subsamples derived from Sample 1); furthermore the ratio of the mean values of $C_{\mathrm{b} 0}$ to those of $C_{\mathrm{m} 0}$ for each series varied between comparatively narrow limits of $0 \cdot 30$ and $0 \cdot 68$. The second, fourth and sixth subsamples of Sample 2 showed high values of $C_{\mathrm{mo}}$ and $C_{\mathrm{b} 0}$ because they had already undergone one period of incubation (see earlier).

It is not yet known whether the observed variability in the values of $C_{\mathrm{m} 0}$ and $C_{\mathrm{b} 0}$ in some groups of subsamples was due to a variable lag-phase or to real variations, resulting perhaps from a failure to subdivide reproducibly the suspended matter in the original sample. Thus the question of the accuracy of the estimates must remain in doubt. On the other hand, the degree of variation is not particularly high and there seem to be no definite grounds for believing that the values were necessarily greatly in error.

At present it is not possible to offer any explanation of the large differences in the 


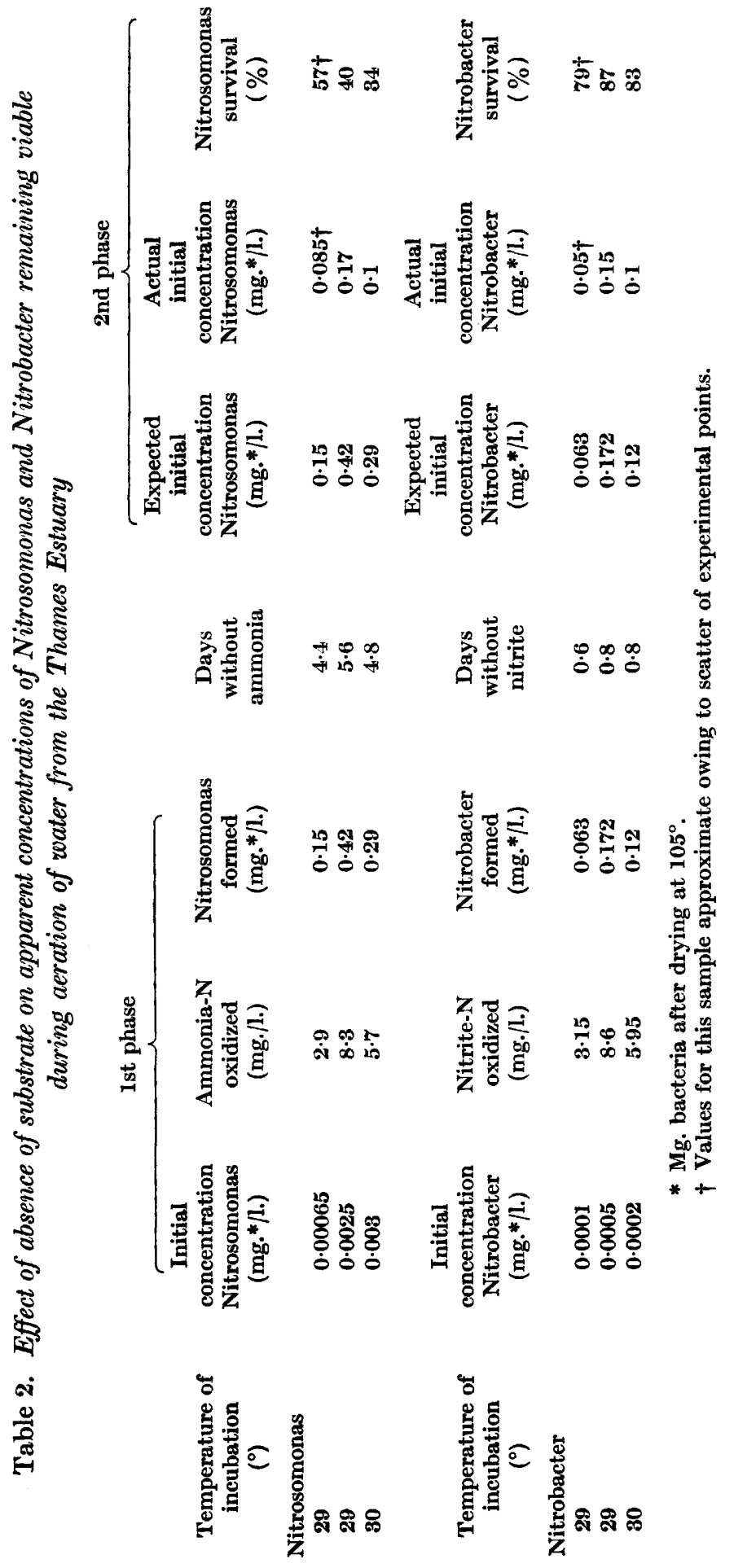


initial concentrations of nitrifying micro-organisms estimated to be present in samples taken from the estuary at different times, other than those due to preaeration of the samples, to which reference has already been made. On the other hand, it would not be surprising if such large variations did occur. Quite apart from the fact that the estuary is far from completely mixed, it would appear that, as indicated below, the organisms did not survive for long periods in the absence of substrate. Moreover, the population density at a given place was also considerably dependent on the concentrations of ammonia, nitrite, and dissolved oxygen, and the variations in these along the estuary. All these factors change markedly with freshwater flow, temperature, and tidal conditions.

Survival of nitrifying organisms. In the case of the subsamples from Sample 2 to which further ammonia was added a day or two after all ammonia originally present had been completely oxidized to nitrate, it appears from data summarized in Table 2 that in this second phase, although the growth constant for both organisms remained substantially unchanged, a good fit to the experimental data could be obtained only by assuming initial numbers of nitrifying bacteria much lower than those calculated to have been formed from the oxidation of the ammonia originally present. Thus for one sample (observed and calculated curves for which are shown in Fig. $1 b$ and other data in Table 2) the concentration of Nitrosomonas at zero days was estimated at $\mathbf{0 . 0 0 3} \mathrm{mg}$./l. From the concentration of ammonia oxidized this would have increased to $0.29 \mathrm{mg}$. $/ \mathrm{l}$. at 5 days, but at the start of the second part of the experiment ( $8 \cdot 8$ days) the concentration of Nitrosomonas was estimated to be only $0.10 \mathrm{mg}$./l. ( $E_{\mathrm{m}}$ was 0.05 for these calculations but assumption of any other value, $E$, would merely multiply each estimated value by $E / 0 \cdot 05)$. It thus appears that a substantial amount of Nitrosomonas may have died during the period when dissolved oxygen was present but ammonia was not; two other experiments of the same kind, results of which are included in Table 2, lead to the same conclusion. Although the data are somewhat variable, the proportion of Nitrobacter apparently surviving during the interval when nitrite was absent, was higher than the corresponding proportion of Nitrosomonas; possibly this is connected with the fact that this period was much shorter than that for which the Nitrosomonas was deprived of substrate (ammonia).

\section{DISCUSSION}

The work shows the usefulness of electronic computers for the rapid integration of differential equations for bacterial growth, particularly those which describe sequential growth of interdependent bacteria and which can only be solved numerically. By these means, estimates of kinetic constants and initial concentrations of bacteria can be obtained quite rapidly from experimental data about the changes in concentration of substrates and products with time in batch cultures. Application of the same method to sequences of enzyme-catalysed reactions could no doubt be made for the purpose of obtaining the velocity-constant for each stage.

The quite accurate fitting of the curves for variations with time in concentrations of ammonia and nitrite in incubated samples containing nitrifying bacteria (assumed to be species of Nitrosomonas and Nitrobacter), using the Michaelis type of growthrate equation, is a further example of the applicability of this type of relation to bacterial growth. Originally developed for enzymic reactions, for which it is widely successful, the Michaelis rate-equation is theoretically based on the idea of reversible 
formation of any enzyme + substrate complex. It is perhaps not surprising that this rate-equation, developed for enzymic reactions in homogeneous solution, applies well to Nitrobacter, in which the nitrite-oxidizing system may be almost in the external medium possibly being situated, according to Boon \& Laudelout (1962), near or at the outer surface of the cell-wall. The ammonia-oxidizing system of Nitrosomonas (involving two stages, the first yielding hydroxylamine) may be similarly situated; if, on the other hand, it is located within the cell, then it can be shown (Rashevsky, 1960) that the Michaelis form of rate-equation would still apply, provided that the rate of transport of ammonia by simple diffusion through the cell-wall to the interior is so high that the concentration of ammonia at the site of reaction is little below that in the external medium. Even this condition need not be met if, instead, transport through the cell-wall is by formation of an intermediate complex or compound, as shown to be the case for phosphate transport into Staphylococcus aureus, for which a Michaelis type expression represents the rate of transport (Mitchell, 1959). Transport by formation of an intermediate complex appears to apply also to amino acids entering Escherichia coli (Britten \& McClure, 1962) and glucose absorption by mammalian cells (see Hober, 1947), and has been suggested for calcium, potassium and sodium entering mammalian cells (Hasselbach, 1962).

The results of the present work support data reported by Buswell et al. (1954) indicating a large temperature coefficient for the growth-rate constant for Nitrosomonas, and show, further, that the saturation constant of ammonia for this organism is somewhat similarly dependent on temperature. The results also show a similar relation between growth-rate constant and temperature for Nitrobacter and confirm qualitatively the previously reported high temperature coefficient for the saturation constant for Nitrobacter. It would appear from the present work that both types of organism tend to die fairly rapidly when aerated in the absence of the relevant energy source. The growth-rate constants of the surviving bacteria were, however, little changed by such treatment, in agreement with Buswell et al. (1954) who showed that it was necessary to keep Nitrosomonas aerated for 12 days without ammonia to produce an alteration in growth-rate constant.

Mr A. L. H. Gameson was responsible for planning the sampling and experimental work in 1960; most of the determinations at that time were made by Mr C. G. Ogden. Sampling and determinations in the 1963 work were done by Mr L. J. Scragg.

\section{REFERENCES}

Bömeke, H. (1946). Über die Ernährungs- und Wachstumsfaktoren der Nitrifikationsbakterien. Arch. Mikrobiol. 14, 63.

Boon, B. \& Laudelout, H. (1962). Kinetics of nitrite oxidation by Nitrobacter winogradskyi. Biochem. J. 85, 440.

Britten, R. J. \& McClune, F. T. (1962). The amino acid pool in E. coli. Bact. Rev. 62, 292.

Buswell, A. M., Shota, T., Lawrence, N. \& van Meter, I. V. (1954). Laboratory studies on the kinetics of the growth of Nitrosomonas with relation to the nitrification phase of the B.O.D. test. Appl. Microbiol. 2, 21.

Department of Scientific and Industrial Research (1964). Water Pollution Research 1963. London: H.M. Stationery Office. 
Downing, A. L. \& Hopwood, A. P. (1965). Some observations on the kinetics of nitrifying activated-sludge plants. Revue suisse Hydrol. (in the Press).

Downing, A. L., Painter, H. A. \& Knowles, G. (1964). Nitrification in the activated sludge process. J. Inst. Sew. Purif. no. 130.

ENGel, H. (1930). Die Oxydationsleistung der Einzelzelle von Nitrosomonas europaea Winogradsky. Arch. Mikrobiol. 1, 445.

ENGEL, M. S. \& Alexander, M. (1958). Growth and autotrophic metabolism of Nitrosomonas europaea. J. Bact. 76, 217.

Fox, L. (1962). Numerical Solution of Ordinary and Partial Differential Equations. Oxford: Pergamon.

GreENwood, D. J. (1962). Nitrification and nitrate dissimilation in soil. II. Effect of oxygen concentration. Plant \& Soil, 17, 378.

HASSElbaCH, W. (1962). ATP-Spaltung und aktiver Ionentransport. Arzneimittel Forsch. 12, 877.

Herbert, D., Elsworth, R. \& Teluing, R. C. (1956). The continuous culture of bacteria: a theoretical and experimental study. J. gen. Microbiol. 14, 601.

Hinshelwood, C. N. (1946). The Chemical Kinetics of the Bacterial Cell. Oxford: Clarendon Press.

Hober, R. (1947). Physical Chemistry of Cells and Tissues. London: J. and A. Churchill.

Hofman, T. \& LeEs, H. (1953). The biochemistry of the nitrifying organisms. 4. The respiration and intermediary metabolism of Nitrosomonas. Biochem. J. 54, 579.

Laudelout, H. \& van Tichelen, L. (1960). Kinetics of the nitrite oxidation by Nitrobacter winogradskyi. J. Bact. 79, 39.

LEES, H. (1952). The biochemistry of the nitrifying organisms. 1. The ammonia-oxidizing systems of Nitrosomonas. Biochem. J. 52, 134.

LEES, H. \& Simpson, J. R. (1954). The biochemistry of the nitrifying organisms. 5. Nitrite oxidation by Nitrobacter. Biochem. J. 65, 297.

Lukehart, P. M. (1963). Algorithm 218. Kutta Merson. Commun. Ass. comput. 6, 737.

Ministry of Housing and Local Government (1956). Methods of Chemical Analysis as applied to Sewage and Sewage Effluents. London: H.M. Stationery Office.

Mrtchell, P. (1959). Biochemical cytology of micro-organisms. A. Rev. Microbiol. 13, 407.

Monod, J. (1942). Recherches sur la Croissance des Cultures Bactériennes. Paris: Hermann.

Novick, A. \& SziLARD, L. (1950). Experiments with the Chemostat on spontaneous mutations of bacteria. Proc. nat. Acad. Sci., Wash. 36, 708.

Rashevsky, N. (1960). Mathematical Biophysics, 3rd edn., vol. 1, p. 83. New York: Dover.

Skinner, F. A. \& Walker, N. (1961). Growth of Nitrosomonas europaea in batch and continuous culture. Arch. Mikrobiol. 38, 339. 